\title{
Factors associated with patient Satisfaction with Anaesthetic care at A Tertiary Care Hospital
}

\author{
Dr. Priyank Savaj, MBBS, MD, Resident \\ Dr. Shaila S Kamath, MBBS, MD. Professor and HOD \\ *Dr.Sunil B V, MBBS, MD, Associate professor \\ Department of Anaesthesia, Kasturba medical college, Mangalore, Manipal academy \\ of higher education.
}

\begin{abstract}
:
Background: Patient satisfaction with Anaesthesia care is an important variable which reflects health care service provided and is quality indicator for Anaesthesia care. Postoperative anaesthesia visits are important in reducing the dissatisfaction during perioperative period.
\end{abstract}

Method: This was a prospective observational Study, conducted in a tertiary care hospital. 150 patients who underwent general anaesthesia for elective surgeries were interviewed with Standardized questionnaires. Questions were related to pre-operative, intraoperative, postoperative anaesthetic care and anaesthetic related complications. Data was entered in Microsoft excel and analysed using SPSS software version 25 (IBM). Chi square test was used to assess the association between each factor \& the overall dissatisfaction of patient.

Result: From total of 150 patients, 145(96.7\%) were satisfied and 5(3.3\%) were dissatisfied with overall anaesthetic care. Factors that associated with patient dissatisfaction were pain during swallowing/sore throat (42.9\% $p=<0.0001)$, nausea/vomiting (33.3\% $p=<0.001)$ and shivering $(15.4 \% p=0.011) .17 .3 \%$ of the patients expressed their dissatisfaction during perioperative visits, which was finally reduced to $3.3 \%$ by additional anaesthesia visits.

Conclusion: overall Patient satisfaction was $96.7 \%$ which is high and acceptable. Patients dissatisfaction rate can be improved with post-operative anaesthesia visits.

Key words:, quality indicator, anaesthesia care, postoperative complications. Patient satisfaction

\section{INTRODUCTION}

Quality of health care has been defined as the degree to which health service increases the odds of desired health outcome which compatible with present professional knowledge ${ }^{[1,2]}$. Continues improvement in the quality of patient care is always a priority work that happens in all institutions and the loopholes are usually identified by the feedback reports.

The best way to access the outcome from the patient point of view is patient satisfaction with health care ${ }^{[3]}$. Patient satisfaction is an important measure of quality of care which can be used to evaluation of structure, process and outcome of service ${ }^{[2,4]}$. In this era of increasing usage 
of internet and social media, patient satisfaction with health care has grown more importance. Patient can easily share their positive or negative experience with others, which can encourage or discourage other people to seek health services from that hospital.

Measuring patient satisfaction is complex concept which involve physical, mental, emotional and social status ${ }^{[5]}$. Factors which contribute to patient satisfaction are accessibility and convenience of service, interpersonal relations, competence of health professional, patients own expectation and adverse outcome ${ }^{[6,7,8]}$. There are some studies in anaesthesia that have measured patient satisfaction and many of them are limited to day-care patients ${ }^{[9,10]}$.

This kind of Survey data can be used to know the areas where action is needed. Consultant can use the finding of such survey to improve quality of hospital care ${ }^{[11]}$. Pain is the most important Couse of patient dissatisfaction in the perioperative period followed by other complications like nausea and vomiting, sore throat and shivering ${ }^{[12]}$. Preoperative and post-operative visit by anaesthetist are important in improving the patient satisfaction. We tried to concentrate on the miscellaneous causes of perioperative discomfort as they are not studied in previous studies. In our study we planned to assess patient satisfaction with anaesthesia care, by formulating questionnaire for post-operative patients to identify the factors associated with patient dissatisfaction and improve patient care.

\section{METHODS AND MATERIALS}

The study was an prospective Observational study done in a tertiary care hospital. After approval from institutional ethics committee, the study was carried out in 150 adult patients who have undergoing elective surgery for which general anaesthesia was given. informed consent was obtained and they were explained about the study during pre-anaesthetic evaluation. Patients between the age group 18 to 70 years, ASA physical status 1 and 2, general anaesthesia duration between half an hour to 3 hours were included in the study. Patients who refused to participate in the study, emergency cases, cases done under regional anaesthesia, patients with mental illness, patient's age less than 18 or more than 70 , major surgical procedures were excluded from the study. Study was registered with clinical trial registry with no.CTRI/2020/03/023764. All patients were seen on the previous day of surgery. They were premedicated with inj fentanyl $2 \mu \mathrm{gm} / \mathrm{kg}$ and midazolam $0.03 \mathrm{mg} / \mathrm{kg}$. anesthesia was induced with propofol $2 \mathrm{mg} / \mathrm{kg}$ and vecuronium $0.1 \mathrm{mg} / \mathrm{kg}$ was used for intubating the patients. endotrachial cuffs were inflated with air and cuff pressures were kept within safe limits. All high risk patients received prophylactic antiemetic medication before extubation. Multimodal analgesia approach was used to tackle the post operative pain which were kept below or equal to 3 using visual analogue scale (VAS). Major surgical procedures that lasts for more then 2 hours were excluded from the study. Questionaries were asked to all patients who participated in the study at the end of 4 hours in the recovery area before shifting to the ward.

Sample size was calculated using the formula: $\mathrm{n}=\frac{Z^{2} P Q}{d^{2}}$ where $\mathrm{Z}=1.96$ at $5 \%$ level of signification, $\mathrm{P}=$ Prevalence $=16 \%, \mathrm{Q}=1-\mathrm{P}=1-0.16=0.84, \mathrm{~d}=$ Effect size $=6 \%$ 
Minimal sample size required for study is 144 . Sampling Method used was convenient nonprobability sampling. Data was entered in Microsoft excel and analysed using SPSS software version 25 (IBM). Chi square test was used to assess the association between each factor $\&$ the overall dissatisfaction of patient.

\section{QUESTIONNAIRE}

Factors related with pre-operative anaesthetic evaluation.

1. Did the anaesthetist visit you before surgery?

Yes No

2. Did the anaesthetist provide you enough information about the Anaesthesia?

$$
\text { Yes No }
$$

3. Did you get opportunity to select type of the anaesthesia?

$$
\text { Yes No }
$$

4. Did the anaesthetist provided any opportunity to ask questions?

$$
\text { Yes No }
$$

\section{Factors related with intra-operative anaesthetic management}

5. Did the anaesthetist take your privacy into consideration in the operating room?

$$
\text { Yes No }
$$

6. Did you experience any pain with induction of the anaesthesia?

$$
\text { Yes No }
$$

7. Did you experience any pain intra-operative?

$$
\text { Yes No }
$$

8. Do you remember anything about the intra operative period?

$$
\text { Yes No }
$$

\section{Factors related with post-operative anaesthetic care}

Did the anaesthetist come to see you after the operation?

$$
\text { No Once More than once }
$$

Did you have any complaints after the operation?

$$
\text { Yes No }
$$

Did the anaesthetist treat your complaints?

Yes

No

Factor related with anaesthesia related complication

\begin{tabular}{|c|}
\hline Did you have any pain during swallowing after the operation? \\
Yes No \\
\hline Did you have nausea/vomiting after the operation? \\
Yes No \\
\hline
\end{tabular}


Did you experience shivering after the operation?

Yes No

Are you satisfied with the overall anaesthesia care?

Satisfied Dissatisfied

\section{RESULTS}

A total of 150 patient, who underwent general anaesthesia, were included in the study. Patients underwent surgeries under orthopedic(23\%), gynecology (22\%), general surgery(55\%) . 72 female and 78 male patients participated in our study with Mean Age of 38 \pm 12.8 years. Demographic features were comparable between age and gender of study population.

Factor related with Pre-operative anaesthetic evaluation, Out of 150 patient, 150(100\%) patients were visited by anaesthetist before surgery, and were given adequate information about anaesthesia. All 150(100\%) patients were given chance to ask questions and to choose the type of anaesthesia.(fig 1)

Factors related with intra-operative anaesthetic management, Out of 150 patients, $150(100 \%)$ patients privacy was kept by anaesthetic. All 150 patients did not felt pain during induction of anaesthesia or intra operatively. None of patient were able to remember anything about intra-operative period.(fig 1)

Factors related with post-operative anaesthetic care, From 150 patient, 128(85.3\%) were visited once, $22(14.7 \%)$ were visited more than once. All the patient who had post-operative complaints were seen and treated $(100 \%)$ for their complaints (fig-1)

Factors related with anaesthetic related complication, From 150 patients, $7(4.7 \%)$ had pain during swallowing, 6(4\%) had nausea/vomiting and $13(8.7 \%$ ) had shivering post-operative (fig $-1)$.

$26(17.3 \%)$ patients had some complication during perioperative period. 7 patients who had post-operative difficulty in swallowing, 3(43\%) patients expressed displeasure with anesthetic care $(\mathrm{p}=<0.001 \mathrm{HS})$. Out of 6 patients who had post-operative nausea/vomiting, $2(33 \%)$ patients were not satisfied with anesthetic care $(\mathrm{p}=<0.001)$, which was statistically significant .Out of 13 patient who had post-operative shivering, 2(15.3\%) patients were dissatisfied with anesthetic care $(\mathrm{p}=<0.001)$, which was statistically significant.(fig 2$)$

Patient satisfaction with overall anaesthetic care: $145(96.7 \%)$ patients were satisfied and $5(3.3 \%)$ were dissatisfied with the overall anesthetic care (Fig 3). 


\section{DISCUSSION}

Patient satisfaction is the measure of quality, and providers' insights into various aspects of medicine, including the effectiveness of their care and their level of empathy. In our study patient satisfaction with anaesthetic care at our tertiary care hospital was $97 \%$. Which is more than study done in Gondor University by Endal Gebreegziabher et al in 2013 which had patient satisfaction of $65 \%$ which is related to preoperative patient visit. We have visited all our patients on the previous day for evaluation and following operation for which they have not raised any dissatisfaction regarding preoperative visit. In their study patient dissatisfaction due to post operative complication was $21 \%$ compared to $17 \%$ in our study. ${ }^{[12]}$. They noticed post operative nausea in $21 \%$ of there patients compared to $4 \%$ in our study. This is probably due to the routene use of prophylactic antiemetics in all high risk individuals for post operative nausea and vomiting. We visited 22 patients more then once in the post operative period which reduced overall patient dissatisfaction rate to $3.3 \%$. we stress the need for post operative routine visits by anaesthetist as they can identify, treat the complications and give explanations which will reduce patients anxiety.

In a study conducted by P.S Myles et al, at Alfred hospital Australia, 96.8\% patient were satisfied with anaesthetic care which is similar to our study. In their study there was a strong relation between patient dissatisfaction with post-operative pain(24\%), and nausea vomiting $(9.1 \%)$. In our study incidence of nausea/vomiting was seen in 6 patients $(4 \%)$ and we managed post operative pain using multi modal approach with the help of both subjective and objective VAS scoring method. They also observed intraoperative patient awareness $(0.11 \%$ incidence) which was also associated with patients dissatisfaction, while in our study none of the patient had complaint of intra-operative awareness $(0 \% \text { incidence })^{[13]}$.

Adel Ali Alshehri et al, have found overall level of satisfaction with anaesthetic care was $95.2 \%$ and dissatisfaction was mainly related to post-operative nausea/vomiting $(11.1 \%)$ and pain(12.4\%). There results of patient satisfaction were high, $95.2 \%$ similar to our study ${ }^{[14]}$.

Main factor for patient dissatisfaction were related to post-operative complication and are not associated with pre or intra operative anesthetic management.

From our study we conclude that the overall percentage of patient who were satisfied with anesthetic care was $97 \%$ at our tertiary care center. Post-operative anesthesia related complications like sore throat, nausea vomiting, and shivering were the major determinant factor for patient dissatisfaction in our set up. With the better premedication and protocol measures we can reduce the incidence of post-operative complications and increase the patient's satisfaction level.

Limitation in our study was the post operative pain which is the main factor associated with patient dissatisfaction in various other studies was not considered and bigger and wider study may be needed to identify the problem area and solutions.

\section{ACKNOWLEDGEMENT:}

We would like to acknowledge the support of Kasturba Medical College Mangalore, Manipal Academy of higher education for conducting the study. 


\section{REFERENCES:}

1. Wacker, Johannes. Measuring and monitoring perioperative patient safety: a basic approach for clinicians. Current Opinion in Anaesthesiology: December 2020 - Volume 33 - Issue 6 - p 815-822

2. Eichhorn JH. The anesthesia patient safety foundation at 25: a pioneering success in safety, 25th anniversary provokes reflection, anticipation. Anesth Analg 2012; 114:791-800.

3. Capuzo M, Alvisi R. Is it possible to measure and improve patient satisfaction with anesthesia? Anesthesiol Clin.2008; 26:613-26.

4. Pitt V, Lowe D, Hill S, Prictor M, Hetrick SE, Ryan R, Berends L. Consumer-providers of care for adult clients of statutory mental health services. Ochrane Database Syst Rev.2013 Mar 28;(3):CD004807

5. Heidegger T, Husemann Y, Nubling M, Morf D, Sieber T, Huth A. Patient satisfaction with anaesthesia care: development of psychometric questionnaire and benchmarking among six hospitals in Switzerland and Austria. Br J Anaesth.2002; 89:863-72.

6. De Brún, C, Howell, F, Bedford D. Corcoran R, Kelly A . Outpatient experiences in acute hospitals. Ir J Med Sci 171, 89-93 (2002). https://doi.org/10.1007/BF03168960.

7. Myles P S, Reeves M D S, Anderson H, Weeks A M. Measurement of Quality of Recovery in 5672 Patients after Anaesthesia and Surgery. Anaesth Intensive Care.2000 Jun;28(3):27680. doi: 10.1177/0310057X0002800304.

8. Farooq F, Khan R, Ahmed A. Assessment of patient satisfaction with acute pain management service: Monitoring quality of care in clinical setting. Indian Journal Anesthesia.2016: 60 ( 4 ) ; 248-252

9. Kleefstra S M, Kool R B, Zandbelt L C, de Haes JCJM. An instrument assessing patient satisfaction with day care in hospitals. BMC Health Serv Res. 2012; 12: 125.

10. . Sam CJ, Arunachalam PA, Manivasagan S, Surya T. Parental Satisfaction with Pediatric DayCare Surgery and its Determinants in a Tertiary Care Hospital. J Indian Assoc Pediatr Surg. 2017 Oct-Dec;22(4):226-231. doi: 10.4103/jiaps.JIAPS_212_16. PMID: 28974875; PMCID: PMC5615897.

11. Benwu K M, Gebremedhin H G. A prospective study on elective surgical inpatient satisfaction with perioperative anaesthesia service at Ayder comprehensive specialized hospital, Mekelle, Ethiopia. BMC 2019.Apr 1;(19)1:46

12. Gebremedhn EG, Chekol WB, Amberbir WD, Flatie TD. Patient satisfaction with anaesthesia service and associated factor at the University of Gondar Hospital, 2013: a cross-sectional study. BMC Res Notes.2015;8:377

13. Myles PS, Williams DL, Hendrta M, Anderson H, Weeks AM. Patient satisfaction after anaesthesia and surgery: results of a prospective survey of 10811 patients. $\mathrm{Br} \mathbf{J}$ Anaesth.2000;84(1):6-10

14. Alsheri AA, Alomar YM, Mohammed GA, Al-Fozan MS, Al-Harbi MS, Alrobai KA, et al. A survey on postanesthetic patient satisfaction in a university hospital. Saudi J Anaesth.2015;9(3):303-5. 


\section{Figures:}

Fig 1; Pre, intra and post operative Factors related to anesthesia

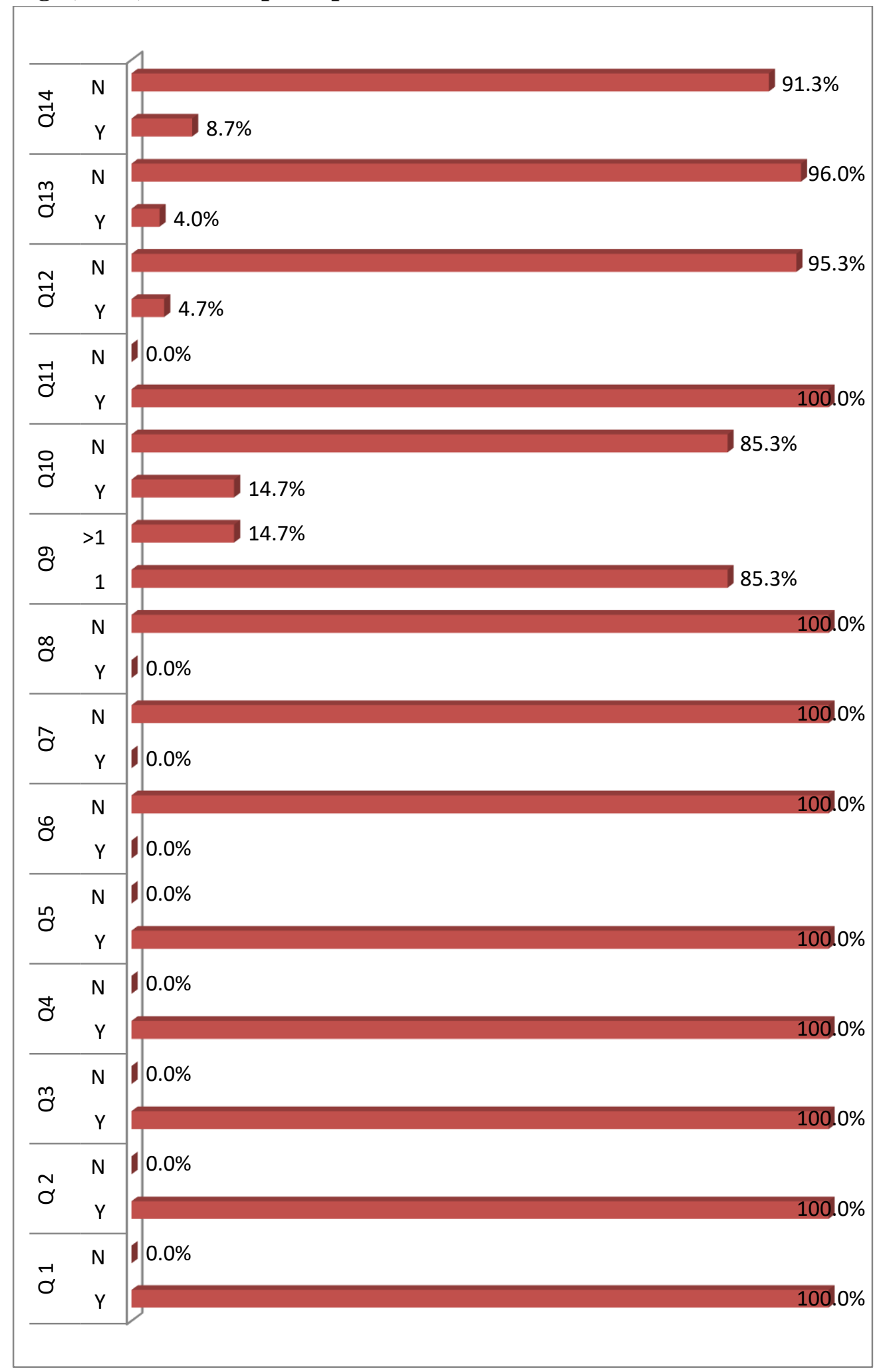


Figure 2: patient satisfaction/dissatisfaction

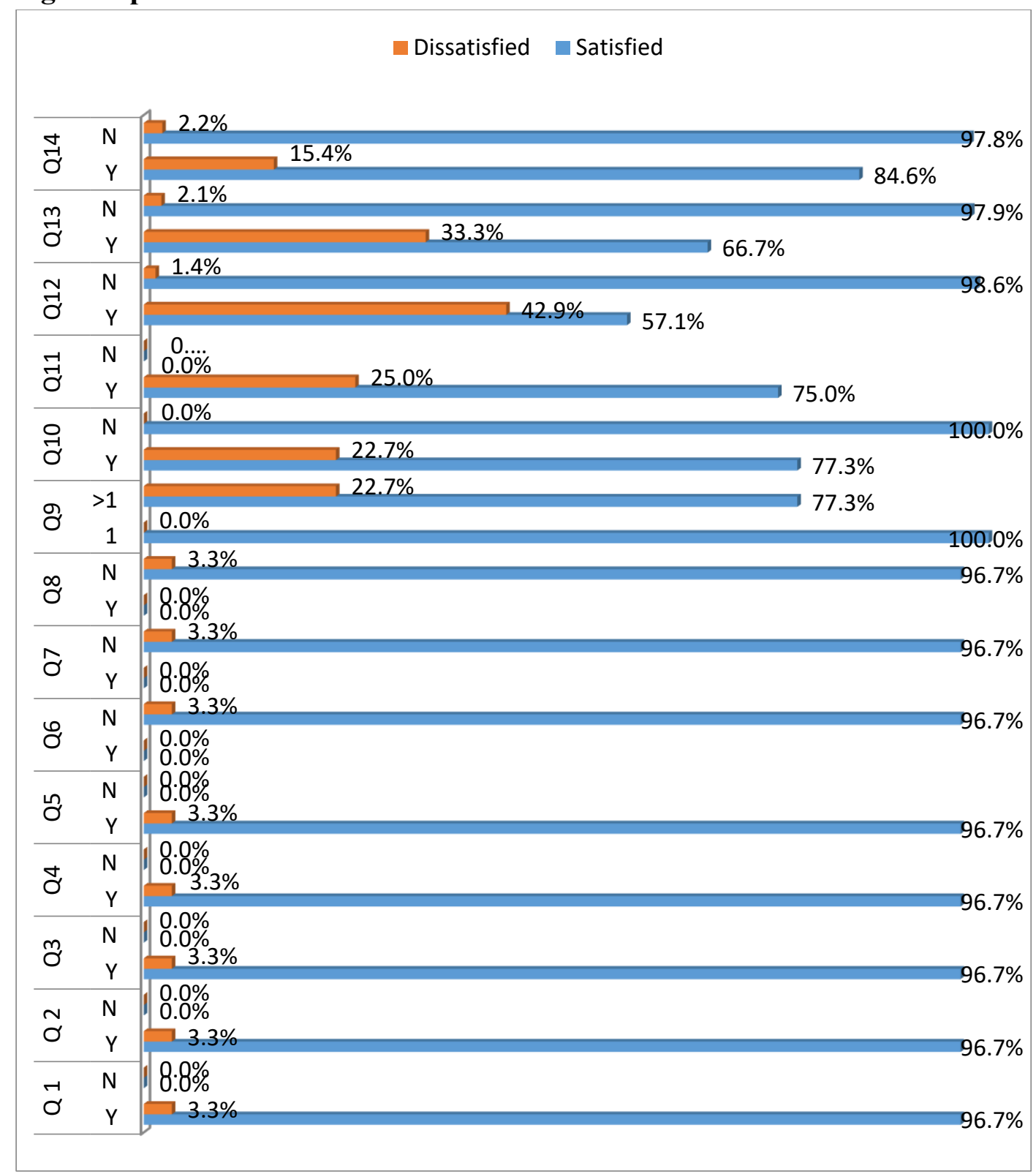

Figure 3; overall patients satisfaction/dissatisfaction

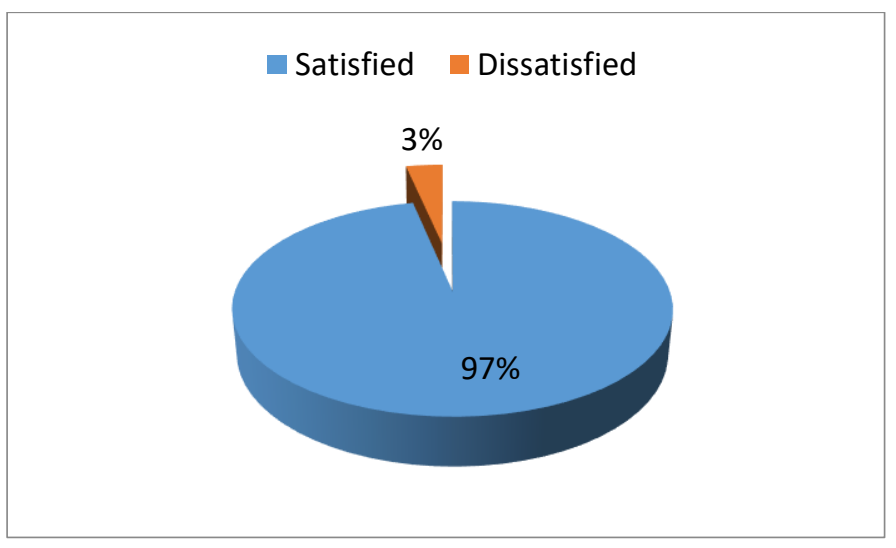

